\title{
A PATERNIDADE E FATORES ASSOCIADOS AO ENVOLVIMENTO PATERNO
}

\author{
PATERNITY AND FACTORS ASSOCIATED WITH PATERNAL INVOLVEMENT
}

\section{MARIANA SCHUBERT BACKES}

ANA PAULA SESTI BECKER

MARIA APARECIDA CREPALDI

\section{MAURO LUÍS VIEIRA}

Programa de PósGraduação em Psicologia, Universidade Federal de Santa Catarina (UFSC), Florianópolis, SC, Brasil.
RESUMO: No cenário atual, pode-se observar uma mudança nos papéis desempenhados pelos pais e mães na interação com seus filhos. A paternidade, por exemplo, passou a ser alvo das pesquisas científicas recentemente, tendo em vista a maior participação do pai na vida dos filhos. Dessa forma, esta pesquisa teve como objetivo identificar os fatores que interferem no envolvimento paterno de pais (homens) de crianças entre quatro a seis anos. Trata-se de um estudo exploratório descritivo, de natureza qualitativa, cujos dados foram coletados através de uma entrevista semiestruturada, a qual foi analisada pela técnica da análise de conteúdo categorial temática, utilizando-se 0 software Atlas.ti. Da análise das entrevistas emergiram quatro categorias: Vivência da paternidade; Responsabilidade; Interação pai-filho e Fatores que interferem no envolvimento paterno. Neste artigo serão apresentados os resultados da última categoria, por estarem diretamente relacionados com 0 objetivo deste estudo. Os resultados apontam que o modelo de paternidade que os participantes tiveram de seus próprios pais, além das relações que estabelecem com a mãe da criança, as características pessoais dos pais e dos filhos e, ainda, a rede de apoio que possuem, constituíram-se em aspectos que repercutiram no envolvimento paterno.

PALAVRAS-CHAVE: pai; paternidade; envolvimento paterno; criança; família.
ABSTRACT: Currently, there is a change in the roles played by parents in interacting with their children. For example, paternity has become the target of scientific research recently, in view of the father's greater participation in the lives of his children. Thus, this research aimed to identify the factors that interfere in the paternal involvement of parents (men) of children between four and six years. It is an exploratory descriptive study, of qualitative nature, whose data were collected through a semi-structured interview; which was analyzed by the thematic categorical content analysis technique, using Atlas.ti software. From the analysis of the interviews emerged four categories: Paternity experience; Responsibility; Parentchild interaction and Factors that interfere with parental involvement. In this article the results of the last category will be presented, because they are directly related to the objective of this study. The results indicate that the participants' paternity model of their own parents, in addition to the relationships established with the child's mother, the personal characteristics of the parents and the children, and the support network they have, were constituted aspects that had repercussions on parental involvement.

KEYWORDS: father; fatherhood; paternal involvement; child; family.
Recebido em: 30/12/2017 Aprovado em: 15/04/2018

\section{INTRODUÇÃo}

Nas últimas décadas, importantes mudanças no funcionamento e na estrutura familiar têm se apresentado e papéis sociais atribuídos a homens e mulheres estão em constante transformação; o que implica novas definições e expectativas sobre que funções pais e mães devem desempenhar e compartilhar no contexto familiar (Grzybowski \& Wagner, 2010; Matos, Magalhães, Féres-Carneiro, \& Machado, 2017; Silva \& Piccinini, 2007) quanto ao cuidado dos 
filhos e à divisão de tarefas domésticas (Wagner, Predebon, Mosmann, \& Verza, 2005).

Tais mudanças são observadas nas funções desempenhadas pelos pais e mães na interação com seus filhos, o que pode ser explicado por alguns fatores, dentre os quais a valorização da mulher no mercado de trabalho. Portanto, as tarefas domésticas e o cuidado com as crianças passaram a ser compartilhados entre o casal e o pai começou a participar de modo mais efetivo nas atividades com seu(a) filho(a) e a compartilhar responsabilidades na educação (Bossardi, Gomes, Vieira, \& Crepaldi, 2013; Bueno \& Vieira, 2014; Dessen \& Ribeiro, 2013).

Ao se considerarem as transformações no âmbito familiar, alguns trabalhos de pesquisa têm investigado o envolvimento paterno e os impactos deste fenômeno sobre o desenvolvimento infantil (Cia, Pamplin, \& Williams, 2008; D’Avila-Bacarji, Marturano, \& Elias, 2005; Ferreira, \& Triches, 2009; Gomes, 2015; Grzybowski, \& Wagner, 2010; Lamb, Pleck, Charnov, \& Levine, 1985; Paraventi, Bittencourt, Schulz, Souza, Bueno, \& Vieira, 2017).

A partir da década de 1970 emergiu o interesse pela temática do envolvimento paterno e, segundo Lamb (2000), o panorama geral das pesquisas indica que o pai tem se envolvido de diferentes formas nos cuidados com os filhos e que isso reflete positivamente no desenvolvimento das crianças de diferentes formas. Ele pode auxiliar nos cuidados básicos com o(a) filho(a), estabelecer limites e estimular o desenvolvimento da criança, pode auxiliar no controle da agressividade, competitividade, habilidades sociais, bem como no seu desenvolvimento motor (Backes, 2015; Cabrera, Tamis-LeMonda, Bradley, Hofferth, \&
Lamb, 2000; Dubeau, Devault, \& Paquette, 2009; Paquette, 2004; Silva \& Piccinini, 2007).

Nesta pesquisa, adota-se o conceito proposto por Lamb (2000) para a definição de envolvimento paterno, o qual compreende três dimensões: interação, disponibilidade e responsabilidade. Entende-se por interação o tempo em que o pai está com a criança, seja no auxílio nas tarefas escolares, alimentando-a ou brincando. A disponibilidade refere-se a níveis de interação menos intensos, por exemplo, quando o pai está em um cômodo da casa e a criança em outro, mas o mesmo está acessível ao(a) filho(a) caso este precise. Por último, a responsabilidade relaciona-se às atitudes do pai para garantir o bem-estar dos seus filhos (Lamb, 1997; Lamb et al., 1985). É importante destacar que o envolvimento paterno é um fenômeno psicológico, mas que tem estreita inter-relação com o contexto social, histórico e cultural. Ou seja, assume-se, no presente artigo, a perspectiva epistemológica de que o envolvimento paterno é entendido como um processo construido socialmente.

Turcotte e Gaudet (2009) apresentam três diferentes domínios que influenciam no envolvimento paterno: as características pessoais do pai, o contexto familiar e o ambiente social. Apesar de existirem controvérsias, resultados da literatura indicam que os homens que tiveram uma relação e imagem mais positiva de seus pais na infância estão mais propensos a participar ativamente no cuidado e na relação emocional com a criança. Isso denota a importância das relações intergeracionais na transição para a paternidade e na forma de exercê-la (Bolze, 2016; Bouchard, 2012; Cabrera et al., 2000; Turcotte \& Gaudet, 2009). 
As atitudes e crenças sobre os papéis de gênero são características que podem influenciar nas condutas e responsabilidades assumidas pelos pais, de acordo com sua concepção das funções que se devem ao pai ou à mãe (Paraventi et al., 2017). Além disso, observa-se que o sentimento de competência parental é um determinante importante na motivação dos homens para investir mais na relação com a criança. As características sociodemográficas, como a idade do pai e o nível socioeconômico, também exercem influência no envolvimento paterno (Cabrera \& Bradley, 2012). Entretanto, para Souza e Benetti (2008), verificou-se que a idade do pai não interfere no envolvimento paterno, mas sua escolaridade sim, ou seja, quanto maior sua formação no ensino, mais este participa nos cuidados de seus filhos.

Considerando o tema estudado neste artigo, adota-se uma visão socioconstrucionista do fenômeno, ou seja, admite-se que cada sujeito significa o mundo a partir da sua própria experiência, o que indica que há diversas concepções de realidade construidas por diferentes observadores. Neste processo de descrição dos fenômenos a narrativa de cada indivíduo adquire fundamental importância, já que é por meio das narrativas que o homem se expressa no mundo. O construcionismo social situa a linguagem no papel central de sua teoria, pois, conforme Grandesso (2000), a linguagem refere-se a um processo interativo, elaborado nos espaços compartilhados de pessoas em relação umas com as outras.

Neste contexto, o construcionismo social busca encontrar nos discursos dos sujeitos as respostas para as indagações sobre os aspectos investigados. Assim, considera-se que o discurso não se constitui em algo separado, mas que é construído nas relações sociais que o sujeito desenvolveu em sua vida, e suas experiências cooperam para moldar suas opiniões e suas atitudes. Conforme afirmam Gergen e Gergen (2010), a construção social não é de autoria de um único indivíduo, pois ela pressupõe um compartilhamento significativo entre diferentes comunidades. Assim sendo, a linguagem adquire total importância para o construcionismo social, já que é através dela que se constrói o mundo, e não o representa em sua totalidade. Dessa forma, neste trabalho são abordados os múltiplos discursos dos participantes a respeito da paternidade, como cada um dos entrevistados vivenciou essa experiência e como cada um enxerga os fatores que podem influenciar no processo de ser pai.

Por considerar que o fenômeno do envolvimento paterno representa uma temática emergente e multidimensional, pois explora de modo específico os diferentes aspectos da relação entre pai e criança, bem como busca aprofundar o impacto do envolvimento do pai sobre o desenvolvimento infantil, este estudo apresenta como objetivo identificar os fatores que interferem no envolvimento paterno de pais (homens) de crianças entre quatro a seis anos.

\section{MÉTODO}

A pesquisa se caracteriza como um estudo de abordagem qualitativa, tendo em vista a finalidade de aprofundar os fatores que influenciam o envolvimento paterno, uma vez que a abordagem qualitativa possibilita ter acesso às experiências, produções de sentido em como as pessoas constroem o mundo à sua volta, crenças e atitudes dos sujeitos dentro do seu contexto (Flick, 2009). Em relação à temporalidade, trata-se de um estudo transversal, visto 
que foi realizado em um momento determinado, no espaço e no tempo atual, da trajetória de vida dos participantes. Esta pesquisa apresentou um delineamento exploratório-descritivo, pois se propôs a conhecer com maior profundidade a temática proposta e descrever as características do fenômeno estudado (Sampieri, Collado, \& Lucio, 2013).

\section{Participantes}

Participaram do estudo 20 pais (homens) de crianças entre 4 a 6 anos de idade. Os pais, biológicos ou não, moravam ou já haviam morado com a criança por pelo menos um ano. Alguns participantes moravam com a mãe da criança e outros eram separados. Foi incluído na amostra apenas o pai que, quando do nascimento da criança focal, já havia completado 18 anos. Metade dos participantes era pais de meninas e a outra metade de meninos. A média de idade dos pais foi $37,60(\mathrm{DP}= \pm 8,33)$; o mais novo tinha 26 anos e o mais velho, 60 . Verificou-se que quatro pais possuíam Ensino Superior Incompleto, seis haviam concluído o Ensino Superior e 10 possuíam nível de pós-graduação, gerando uma média de 17,55 (DP: $\pm 3,42$ ) anos concluídos de estudo. As profissões dos pais foram variadas, sendo que a maioria era professor universitário ou servidor público de cargo administrativo. A média de renda do pai foi 6315,00 (DP: $\pm 3277,19$ ), com mínimo de 2000,00 reais e máximo de 15000,00 reais. De acordo com as respostas obtidas, 13 dos pais trabalhavam 40 horas semanais e cinco trabalhavam 30 horas, um relatou 10 horas semanais e outro 44 horas semanais.

A coleta de dados aconteceu entre os meses de abril e maio de 2014, em uma cidade do sul do Brasil, tendo sido realizada em uma Instituição de Educação Infantil, a qual atua na educação de crianças na faixa etária delimitada. A criança focal ${ }^{1}$ teve idade entre 4 e 6 anos e a escolha por essa faixa etária se justificou pelo fato de que após os 3 anos de idade, as crianças demonstram maior abertura para estabelecerem outras relações além da relação materna. Utilizou-se como critério de exclusão pais cujo filho(a) tivesse algum tipo de deficiência, uma vez que a deficiência se caracterizaria como uma variável interveniente no estudo.

\section{Instrumentos}

Utilizou-se a entrevista Semiestruturada de Envolvimento Paterno, elaborada por Bueno, Vieira e Crepaldi $(2012)^{2}$ com perguntas adaptadas de Bossardi e Vieira (2012), sendo composta por perguntas que estão divididas nos seguintes itens norteadores: experiência de ser pai, responsabilidade, disponibilidade, interação e, por último, fatores que interferem no envolvimento paterno. As perguntas, de forma geral, investigaram questões referentes a como o pai avalia sua participação na vida do filho(a), quais tarefas ele desempenha com ele, quanto tempo fica junto com a criança, o que faz quando está com ela, que tipo de brincadeiras, sobre o que conversa; se, na percepção do pai, a companheira (mãe) ajuda ou atrapalha sua participação no cuidado da criança e sobre aspectos que facilitam ou dificultam seu envolvimento paterno, entre outras.

\section{Procedimentos e coleta de dados}

O projeto de que derivou este artigo foi oriundo de uma pesquisa de dissertação, sendo apresentado e aprovado pela Instituição de Educação In-
10 termo criança focal é utilizado para definir sobre qual dos filhos o pai respondeu a entrevista.

2 Bueno, R. K., Vieira, M. L., \& Crepaldi, M. A. (2012). Entrevista semiestruturada de envolvimento paterno. Instrumento não publicado. Universidade Federal de Santa Catarina: Núcleo de Estudos e Pesquisas em Desenvolvimento Infantil. 
fantil (IEI), que convidou as famílias enviando-lhes uma Carta-Convite. O projeto foi aprovado pelo Comitê de ética em Pesquisa com Seres Humanos, sob o parecer consubstanciado $n^{\circ}$ 447.932. Procedeu-se um contato telefônico com os pais que assinaram as cartas-convite e confirmaram o interesse na participação, agendando-se um encontro para a coleta de dados. $\mathrm{Na}$ data marcada realizou-se a entrevista, mediante a assinatura do Termo de Consentimento Livre e Esclarecido (TCLE), após a explicação dos objetivos da pesquisa. A entrevista teve duração de aproximadamente 75 minutos e foi realizada nas dependências da Universidade, em sala adequada para tal procedimento. A entrevista foi gravada e, posteriormente, transcrita para análise.

\section{Análise de dados}

Os dados foram analisados com base na técnica de análise de conteúdo categorial temática proposta por Bardin (2011). Tal análise, por meio da busca dos eixos temáticos, propõe-se a desvendar os núcleos de sentido do discurso do entrevistado. A análise foi organizada a partir de: a pré-análise; a exploração do material; e o tratamento dos resultados, pela inferência e interpretação. A categorização empregou o processo de acervo, em que o corpus é decomposto em microelementos e reconstruído em subcategorias e categorias temáticas mais amplas. Para melhor visualização e organização dos dados, utilizou-se o software ATLAS.ti $5.1^{3}$. Os pais foram nomeados de $\mathrm{P} 01$ a P20.

$\mathrm{Da}$ análise de conteúdo, emergiram quatro categorias temáticas: vivência da paternidade, responsabilidade pela necessidade do(a) filho(a), interação pai-filho(a) e fatores que interferem no envolvimento paterno. Escolheu-se a quarta categoria, referente aos fatores que interferem no envolvimento paterno, para o detalhar e aprofundar a análise apresentada nesse artigo.

\section{RESULTADOS}

Esta categoria engloba todos os elementos que podem influenciar o envolvimento paterno de alguma forma, ou seja, aspectos que facilitam ou dificultam o engajamento e a participação do pai na vida da criança. Está composta por seis subcategorias (fatores ligados à mãe, fatores ligados ao próprio pai, fatores ligados à criança, rede social de apoio, modelo do próprio pai e o que faz de diferente do próprio pai).

$\mathrm{Na}$ subcategoria fatores ligados à mãe, o pai identifica como influência relevante no seu envolvimento com a criança a presença têm sido da mãe e sua relação conjugal. Os pais relataram que a criança opta pela presença da mãe quando essa se mantém por perto, portanto, o pai se mantém mais afastado do filho(a), dedicando-se menos aos cuidados e brincadeiras com a criança. Apenas dois pais relataram que a ausência da mãe facilita o envolvimento deles com a criança, pois na falta dela o(a) filho(a) interage e obedece mais à figura do pai.

A ausência da mãe da minha filha, por incrível que pareça... Quando eu resolvo tomar a iniciativa e quero fazer alguma coisa, eu tenho atenção. Se a mãe da minha filha está junto eu não tenho. Ela (criança) desvia toda a atenção pra mãe dela. Por isso a gente tem se aproximado ultimamente. A mãe dela 
está trabalhando, eu tenho que ficar com ela e com a priminha aí está agilizando muito o processo. (P06)

Os participantes afirmam que a relação que estabelecem com a mãe de seus(as) filhos(as) reverbera na interação com a criança. Mesmo os pais separados relataram ter um relacionamento bom com a mãe da criança. Eles mencionaram tentar separar as questões conjugais e parentais, bem como evitar discutir na frente dos filhos para não afetar o relacionamento com eles. Mas, houve casos em que, quando existiu conflito com a parceira, o pai relatou afastamento do filho(a) ou aproximação demasiada, dando mais atenção com o intuito de compensar por sentir-se culpado pela desavença conjugal.

Já aconteceu de eu ter menos paciência com a minha filha, realmente assim, de a gente ter menos paciência, de não querer brincar... Sim, me afasto um pouco. Já aconteceu também de eu me apegar mais a ela, brincar mais... tem os dois lados assim, tem um lado que eu me afasto, e tem um lado que eu consigo me aproximar mais com ela e faz bem pra mim. E ela assim, no mundo dela, não hum, não percebe tanto quando brigamos. Porque eles percebem, mas, quando alguma coisa tá diferente. (P03)

$\mathrm{Na}$ subcategoria fatores ligados ao próprio pai, identificaram-se características do pai que afetam o envolvimento paterno. Esses atributos estão relacionados ao temperamento e à personalidade do pai e ao momento de vida no qual se encontra, que possibilita ou não maior participação na vida da criança. Os pais afirmaram estar vivendo uma fase tranquila de suas vidas, em que conseguem administrar o tempo para estar com o(a) filho(a), apesar de que gostariam de ter mais disponibilidade, mas a carga horária de trabalho não permite. No que diz respeito à personalidade, os pais admitiram serem bastante comunicativos e espontâneos, e que isso ajuda na relação com o(a) filho(a), pois constroem com ele um relacionamento aberto, em que ambos se sentem muito à vontade um com o outro. Emergiram também relatos de pais que disseram ser muito estressados e acabavam "descontando" nos(as) filhos(as) quando estão nervosos, sendo que essa característica foi considerada como dificultadora do seu envolvimento com a criança: "Eu sou muito estressado, acho que isso me prejudica, porque daí eu não tenho cabeça sabe, não tenho cabeça pra entrar muito em contato com meu filho" (P08).

$\mathrm{Na}$ subcategoria fatores ligados à criança foram apontados os aspectos da criança que interferem no envolvimento. No geral, os pais descreveram seus(as) filhos(as) de maneira bastante positiva, ressaltando qualidades que os motivavam a querer ficar perto deles. $\mathrm{O}$ amor que os pais sentem pela criança, a admiração que o(a) filho(a) tem pelo pai, o gostar de estar com o(a) filho(a) são ressaltados pelos participantes como fatores que facilitam seu envolvimento nos cuidados com o(a) filho(a).

Se não tiver amor, não tem como a pessoa descer ao nível, entender o que está se passando na cabeça deles, entender os desafios e os medos que eles também... vivem né? E as fases também, acima de tudo, cada fase vem definida, saber que eles estão construindo uma faculdade mental, construindo um pensamento, construindo uma... Uma 
referência de segurança, de afeto, é... de super-herói, da figura de super-herói, então tudo isso. (P16)

$\mathrm{Na}$ subcategoria rede social de apoio é destacado o papel da rede de relacionamentos do pai e da família como algo que contribuiu no envolvimento paterno no sentido de fornecer apoio emocional e auxílio nos cuidados com a criança, desde a época do nascimento até hoje. Os pais relataram que o fato de poder contar com alguém, seja da família ou um amigo, lhes dava a sensação de alívio, de não se sentirem sozinhos nessa etapa, e ter pessoas para lhes escutar era algo que os tranquilizava, como exemplo: "Eu conversava muito com meu irmão, me fazia muito bem, não me sentia sozinho nessa parada" (P15).

Ainda a respeito da rede social de apoio, os pais afirmam que à medida que o(a) filho(a) foi crescendo, suas vidas ficaram muito centradas nas relações familiares e sua vida social reduzida às interações dentro do contexto familiar, de modo que os entrevistados assumiam sentir falta do convívio com os amigos.

A subcategoria modelo do próprio pai mostrou como os pais dos participantes agiram como pais, ou seja, como seus próprios pais exerciam a paternidade. Os entrevistados ressaltam que seus pais eram mais ausentes, algumas vezes agressivos e pouco afetivos. O relato a seguir ilustra tal apontamento:

Meu pai era um pai bem rígido. Ele era um cara bem, bem quadradão assim, sabe? Até agressivo às vezes. Mas é normal, filho homem... Mas era assim, ele era rígido, me ensinou coisas de moleque, empinou pipa comigo, me levou pra pescar... Ele nunca admitiu que eu chamasse ele de você, era sempre senhor... Então ele era um cara severo, na realidade... Ele sempre me cobrou muito, eu sempre fui um moleque muito relaxado. (P06)

Também houve casos em que o pai era carinhoso e presente na vida do filho. Prevaleceu o modelo de pai provedor, que trabalhava fora de casa e cuja preocupação central era o sustento da família.

Bem, eu quero dar o carinho e a atenção que ele me proporcionava. A gente sempre sabia que tinha alguém pra ajudar na hora que estragasse tudo, desde a primeira batida no carro. (P04)

A vida dele era muito trabalho, era... Assim, eu vejo que ele se esforçou bastante... Do jeito dele, do jeito de prover as coisas em casa, naquele modelo assim de não deixar faltar, de correr atrás e por isso não tinha tempo e deixava tudo pra minha mãe, os cuidados assim. (P05)

Os participantes disseram que a referência que tiveram para exercer a paternidade foi o próprio pai, tomando como base as condutas boas e questionando as ruins, criando seu próprio jeito de exercer a paternidade.

Eu acho que é uma referência do bem e do mal, entendeu? Não uma referência do tipo "Ai o meu pai era maravilhoso, eu quero ser igual a ele", isso não. Mas sim, eu tinha um pai que tinha coisas boas e coisas ruins, é o meu modelo, e as coisas boas eu tento reproduzir e as coisas ruins eu tento largar... (P01)

$\mathrm{Na}$ última subcategoria, o que faz de diferente do próprio pai, apresen- 
tam-se condutas, valores e sentimentos que o entrevistado afirma reproduzir de outra forma com seus próprios(as) filhos(as). Salienta-se a participação nas tarefas da casa, tendo em vista que os participantes relataram que seus pais não se encarregavam dos cuidados da casa, cujo dever era função exclusiva da mãe. Um entrevistado afirmou que seu pai o tratava de uma maneira totalmente diferente da irmã, destacando que trata seus(as) filhos(as) de maneira igualitária, independente do gênero as cobranças são iguais. Outros pais relataram que valorizam muito a convivência em família e, ao contrário de seu pai, que estava sempre fora de casa, priorizam os momentos com a esposa e filhos. Por último, os entrevistados reconheceram que, apesar de seus pais serem muito preocupados com o trabalho e sustento da casa, no intuito de não deixar faltar nada e oferecer à família uma vida mais confortável, a relação pai-filho(a) careceu da parte afetiva. Esses pais afirmaram que buscaram ser mais carinhosos com seus filhos por acharem que foi um aspecto que faltou com seus próprios pais e que significa algo importante para estabelecerem com seus próprios filhos.

$\mathrm{Eu}$ sempre fui um pai presente. Eu acho que o modelo, eu olhei pra ele e vi tudo aquilo que não era necessário e não deveria se repetir. Então eu procurei trabalhar pra fazer assim. Talvez o erro de um é o preço pros outros aprenderem, não culpo ele por isso. Provavelmente os pais dele nunca conseguiram fazer isso com ele e ele acabou sem um norte, assim. Mas isso fez com que eu me obrigasse a ser um pai melhor. (P02)

Pode-se constatar nesta categoria alguns atributos que o pai considera como fatores que interferem no seu envolvimento paterno. Aponta-se a relevância mencionada pelas heranças intergeracionais na construção de sua paternidade, oriundas da própria relação afetiva que manteve com o seu pai na infância; o que permite refletir sobre os padrões de continuidades e descontinuidades que os entrevistados relataram, a partir da parentalidade que vivenciam com seus(as) filhos(as) ao se tornarem pais. Além desses aspectos, as características pessoais e as relações que estabelece com a mãe da criança, bem como a compreensão quanto ao estágio desenvolvimental do filho(a) e a rede de apoio que possuem, constituíram-se em fatores importantes para a manutenção do envolvimento paterno.

\section{DISCUSSÃO}

Em relação aos fatores que podem interferir no envolvimento paterno, citam-se a relação com a mãe da criança, fatores relacionados ao pai, aspectos ligados ao temperamento da criança, à rede social de apoio e ao modelo de paternidade. A forma como os pais negociam e se relacionam com a mãe da criança é importante e influencia no envolvimento paterno. Quando existe alguma discordância ou conflito entre o casal, os entrevistados revelam dois comportamentos distintos, afastamento ou aproximação dos filhos. Alguns interagem menos com a criança porque ficam impacientes e, ao contrário, outros confessam dar mais atenção aos filhos por sentirem-se culpados, tentando compensar sendo mais presentes.

Bueno (2013), em entrevista com quatro pais, constatou que dois dos participantes não atribuíram diferença em seu envolvimento quando houve algum tipo de conflito com a mãe da 
criança; outro alegou não ter conflito com a companheira e apenas um desses pais admitiu envolver-se mais com o(a) filho(a). Os estudos sobre a relação entre envolvimento paterno e relacionamento conjugal verificam que o pai se envolve menos quando há uma relação conjugal problemática (Bolze, 2011; Bossardi, 2011; Cabrera \& Bradley, 2012; Falceto, Fernandes, Baratojo, \& Giugliani, 2008; Schober, 2012; Simões, Isabel, \& Maroco, 2010; Wagner et al., 2005).

O maior envolvimento paterno pode ser pensado, segundo Andolfi, Claudio, e Saccu (1995) e Gabriel e Dias (2012), como uma resposta para o conflito conjugal. Destaca-se que uma relação conjugal caracterizada como harmônica não se refere, necessariamente, a uma relação conjugal sem conflitos (Schmidt, 2012); o conflito é inerente aos relacionamentos humanos e pode ser positivo, uma vez que pode servir como oportunidade e transformação aos envolvidos (Bolze, 2011). As estratégias de resolução de conflitos adotadas pelos pais devem ser consideradas à medida que os pais que resolvem seus desentendimentos de forma mais construtiva promovem a estabilidade da família e segurança emocional da criança, reduzindo a ansiedade (Bolze, 2016; Davies, Cummings, \& Winter, 2004).

A maior parte dos pais participantes concordou que a mãe influencia na relação com seus filhos, seja incentivando-o a participar dos cuidados ou dificultando e, até mesmo, impedindo a interação do pai com a criança. Quando a mãe motiva o pai a cuidar e a interagir com a criança, o pai diz se sentir valorizado e encorajado exercendo seu papel. Quando, por outro lado, a mãe coloca obstáculos na interação pai-filho(a), por exemplo, proibindo-o de realizar certas atividades com a criança ou tirando sua autoridade, ele declara que se sente desmotivado e se envolve menos com os(as) filhos(as). No estudo de Oliveira (2017), cuja temática norteou o envolvimento paterno no processo de separação conjugal, verificou-se que a falta de autonomia como pai, relacionada à intromissão materna, constituiu-se como um dos fatores negativos associados ao envolvimento paterno antes do divórcio.

Essa influência da mãe no envolvimento do pai com a criança pode ser explicada pelo predomínio do modelo tradicional sobre a divisão dos papéis de gênero e de socialização da paternidade. As mulheres foram criadas para assumirem primeiramente a responsabilidade sobre os filhos (Wagner et al., 2005). Assim, a função paterna é menos definida e codificada do que o papel materno, pois, de acordo com a cultura ocidental, os homens foram menos preparados para assumir o cuidado de uma criança (Turcotte \& Gaudet, 2009). Entretanto, essa dinâmica tem se alterado com o passar dos anos, tendo em vista uma nova configuração de paternidade e de maternidade que tem surgido, em que a criança não pertence exclusivamente à responsabilidade feminina quanto às praticas educativas e de cuidado (Dessen \& Oliveira, 2013; Goetz \& Vieira, 2009; Piccinini, Levandowiski, Gomes, Lindenmeyer, \& Lopes, 2009).

A crescente inserção da mulher no mercado de trabalho tornou-se um dos fatores notórios que contribuiu para o pai compartilhar mais as tarefas domésticas e a se engajar mais no cuidado com os filhos (Dessen \& Oliveira, 2013; Staudt \& Wagner, 2008; Wagner et al., 2005). Contudo, embora as atividades domésticas estejam sendo cada vez mais desempenhadas pelos homens, a literatura aponta que ainda são as mulheres as 
principais responsáveis pelos cuidados dos filhos e da casa (Bossardi, Gomes, Vieira, \& Crepaldi, 2013; Bueno, 2014; Genesoni \& Tallandini, 2009).

Com relação a esse tema, alguns autores (McBride, Brown, Bost, Shin, Vaughn, \& Korth, 2005; Pimenta, Veríssimo, Monteiro, \& Costa, 2010; Schoppe-Sullivan, Brown, Cannon, Mangelsdorf, \& Sokolowski, 2008; Turcotte \& Gaudet, 2009) fazem alusão ao conceito do gatekeepers, uma vez que as mães possuem uma posição familiar privilegiada no sentido de tomar conta dos filhos e do lar; estas podem ficar receosas de que os pais tomem o lugar delas e, portanto, acabam praticando um papel de vigilantes na dinâmica familiar, coordenando o envolvimento dos pais com seus filhos, para garantir o seu poder.

Esse fato assemelha-se a um paradoxo, visto que deflagra uma conduta contraditória das mães que, ao mesmo tempo em que exigem uma participação mais ativa dos homens nas tarefas domésticas, nos cuidados e educação dos filhos, parecem sentir que essa cooperação paterna pode interferir na dinâmica relacional familiar. Tais receios maternos podem fazer com que as mães não estimulem tanto os pais a se esforçarem para ter um papel mais ativo na educação dos filhos, ocasionando, assim, um menor envolvimento paterno. Logo, a maior participação do pai nos cuidados com a criança está relacionada a características da mãe e ao quanto ela permite e abre espaço para isso (Backes, 2015; Lamb, Frodi, Hwang, \& Frodi, 1983; McBride et al., 2005; Monteiro, Fernandes, Veríssimo, Costa, Torres, \& Vaughn, 2010; Pimenta et al., 2010).

Em se tratando dos fatores relativos ao pai, encontrou-se que os pais associam algumas características pessoais suas que facilitam ou dificultam o envolvimento paterno. Entre os principais atributos facilitadores apontam a comunicação e espontaneidade e, como dificultadores, o fato de serem estressados e descontarem nos filhos. De acordo com os participantes, o temperamento da criança também influencia no seu envolvimento. Os pais relataram que o fato de seus filhos se mostrarem, na maior parte do tempo, tranquilos e obedientes, reforçou a sua proximidade nas interações e cuidados com eles.

A rede social de apoio também é evidenciada como um fator que auxilia na criação dos filhos, pois quando os pais podem contar com a ajuda de outros familiares ou amigos próximos, sentem-se mais seguros, apoiados e tranquilos. Desse modo, quando não há presença de pessoas da família extensa por perto auxiliando nos cuidados das crianças (Bustamante \& Trad, 2005), os pais podem ser mais solicitados, o que parece ter ocorrido com os pais desta pesquisa.

As particularidades do pai e do contexto que facilitam seu envolvimento com a criança podem ser pensadas, por meio da teoria bioecológica do desenvolvimento humano, como uma característica pessoal do tipo "disposição", pois parece favorecer os processos proximais e, consequentemente, o envolvimento paterno. Esses fatores relacionados à personalidade do pai vão ao encontro do que Lamb, Pleck, Charnov e Levine (1985), Lamb (1997) e Pleck (1997) afirmam: que o envolvimento paterno é construído e influenciado pela história dos pais com seus próprios cuidadores, características da personalidade e crenças do pai.

A respeito da relação que os participantes possuíam com seus próprios pais, constatou-se, de maneira geral, que os pais dos entrevistados não participavam muito dos cuidados dos 
filhos nem da casa, havendo um predomínio no padrão de pai provedor, o qual trabalhava fora para provimento de bens materiais à família, com restrito envolvimento no âmbito afetivo. Conforme Balancho (2004), os resultados estão de acordo com a percepção social do pai da geração anterior, menos envolvido diretamente com as crianças e exercendo sua autoridade como chefe de família.

Dessa forma, os respondentes dessa pesquisa adotavam como modelo de paternidade um misto de condutas que se baseavam em aspectos que julgavam ser positivos ou negativos, em relação aos próprios pais. Ou seja, reproduziam com os filhos as influências positivas e ressaltaram fazer diferente do que não aprovaram de seus pais. Tais achados estão em consonância com os resultados do estudo de Bolze (2016) que, ao investigar a transgeracionalidade, observou que as táticas de resolução de conflito conjugal utilizadas pelo casal provinham de modelos familiares de seus pais ou antecedentes, que eram mantidas ou descartadas nas relações familiares. Tais modelos eram retransmitidos na relação parental, o que parece indicar padrões de continuidades e descontinuidades na dinâmica familiar.

Diante disso, pode-se constatar que a maneira com que os pais tratavam seus filhos parece estar relacionada aos modelos de criação que receberam de seus pais. Conforme Gabriel e Dias (2011), a forma como o pai percebe seu próprio pai demonstra certa ambiguidade e, ao mesmo tempo, revela que os filhos entendem que seu genitor pode ter tido algumas falhas, mas nem por isso seu modelo de pai se torna totalmente desprezível. Essa compreensão de possíveis erros cometidos pela figura paterna vem da contextualização do momento históri- co que seus pais vivenciaram, ou seja, os filhos relativizam algumas práticas levando em consideração a época em que seus pais viveram (Gabriel \& Dias, 2011). Tal fato foi reafirmado nesta pesquisa, corroborando também os achados de Bueno (2013), nos quais os pais entrevistados reconheceram que a forma de ser pai antigamente era diferente do ser pai nos dias atuais, devido às mudanças sociais e econômicas que ocorrem na contemporaneidade.

A respeito disso, Gabriel e Dias (2011) verificaram que ser filho(a) em um modelo tradicional, no qual, na maioria dos casos, o pai demonstra menos afeto e é mais distante, instiga os homens a desejarem ser um pai diferente. Destaca-se, então, a importância e influência que os pais têm no processo de construção da paternidade que seu filho(a) desempenhará futuramente. Pode-se pensar, assim, que a vivência da paternidade e do envolvimento paterno é construída através das relações familiares desenvolvidas e, também, por meio das relações sociais e contextuais que o sujeito realiza em sua vida, o que contribui para direcionar suas opiniões e atitudes sobre o que é ser pai e como exercer essa função no ciclo vital familiar. Portanto, de maneira geral, constatou-se que os pais estão repensando questões acerca da paternidade e isso é positivo ao passo que vão se conscientizando a respeito de diferentes possibilidades de exercer a paternidade, já que as condutas parentais vêm se alterando atualmente (Bornholdt, Wagner, \& Staudt, 2007).

\section{CONSIDERAÇÕES FINAIS}

De modo geral, os pais relataram aspectos que podem repercutir no envolvimento paterno, no sentido de facilitar ou dificultar o engajamento e a partici- 
pação que mantêm na vida de seus filhos. A presença materna pareceu constituir-se em um fator que interfere na díade pai-filho(a) na medida em que, na ausência da mãe, os pais demonstraram interagir mais com os filhos e obter deles maior obediência. Além disso, o modelo de paternidade que receberam de seus próprios pais apresentou-se como aspectos importantes no envolvimento paterno ao se tornarem pais.

Destaca-se, portanto, a importância em se considerar os padrões de relacionamento transmitidos intergeracionalmente, por exemplo, entre a relação do pai com o seu próprio pai. Essa é a base sobre a qual ele irá construir seu jeito particular de exercer a paternidade, por meio da reprodução de condutas que considerava adequadas e reavaliação de práticas que, na sua opinião, poderiam ser diferentes. É nessa reavaliação de modelos que o sujeito tem a possibilidade de atribuir significado aos fatos que vivencia. Assim, esses significados que os participantes foram construindo em seu modo de experienciar a paternidade tornam-se o alicerce em sua forma de agir, pensar e sentir sobre as relações passadas e presentes que constituem a parentalidade. Os pais dessa pesquisa afirmam demonstrar mais afetividade e participação nas atividades de seus filhos, do que os seus próprios pais foram com eles, o que caracteriza um estilo de pai emergente, o qual se envolve emocionalmente e de forma ativa nos cuidados do(a) filho(a). Acerca disto é importante, também, considerar que o contexto temporal e social entre as gerações divergia do modelo familiar predominante da época, tendo em vista a função paterna que se espera nos dias atuais.

Oportuniza-se, portanto, salientar as especificidades sobre a relação pai-filho(a) no contexto contemporâneo.
Dessa forma, podem ser planejadas ações no âmbito dos setores da saúde, educação e assistência social, com vistas a desenvolver programas de intervenção que atentem para a inclusão do pai na atenção à criança. Isto porque, neste espaços, o interlocutor principal ainda tem sido a figura materna.

No âmbito acadêmico, sugerem-se pesquisas futuras que englobem o acompanhamento longitudinal dos pais pesquisados quanto às semelhanças e diferenças no envolvimento paterno e estrutura familiar ao longo do tempo. Recomenda-se, ainda, investigar a participação do pai em diferentes faixas etárias do(a) filho(a), haja vista que a criança apresenta diferentes demandas ao longo do tempo. Por fim, é importante apontar que estudos sobre a paternidade possibilitam dar voz ao público masculino por oportunizar a maior visibilidade e participação da figura paterna em diferentes contextos da sociedade.

\section{REFERÊNCIAS}

Andolfi, M., Claudio, A., \& Saccu, C. (1995). O casal em crise. São Paulo: Summus.

Backes, M. S. (2015). A relação entre o envolvimento paterno e a abertura ao mundo em pais de crianças entre quatro a seis anos. Dissertação de Mestrado, Programa de Pós-graduação em Psicologia, Universidade Federal de Santa Catarina, Florianópolis, SC.

Balancho, L. S. F. (2004). Ser pai: Transformações intergeracionais na paternidade. Análise Psicológica, 2(22), 377-386.

Bardin, L. (2011). Análise de conteúdo. São Paulo: Edições 70.

Bolze, S. D. A. (2011). A relação entre engajamento paterno e conflito 
conjugal dos pais com crianças de 4 a 6 anos. Dissertação de Mestrado, Programa de Pós-graduação em Psicologia, Universidade Federal de Santa Catarina, Florianópolis, SC.

Bolze, S. D. A. (2016). Táticas de resolução de conflitos conjugais e parentais: Uma perspectiva da transmissão intergeracional. Tese de Doutorado, Programa de Pós-graduação em Psicologia, Universidade Federal de Santa Catarina, Florianópolis, SC.

Bornholdt, E. A., Wagner, A., \& Staudt, A. C. P. (2007). A vivência da gravidez do primeiro filho à luz da perspectiva paterna. Psicologia Clínica, 19(1), 75-92.

Bossardil, C. N. (2011). Relação do engajamento parental e relacionamento conjugal no investimento com os filhos. Dissertação de Mestrado, Programa de Pós-graduação em Psicologia, Universidade Federal de Santa Catarina, Florianópolis, SC.

Bossardi, C. N., Gomes, L., Vieira, M. L., \& Crepaldi, M. A. (2013). Engajamento paterno no cuidado a crianças de 4 a 6 anos. Psicologia Argumento, 31(73), 237-246.

Bouchard, G. (2012). Intergenerational Transmission and Transition to Fatherhood:

A Mediated-Moderation Model of Paternal Engagement. Journal of Family Psychology, 26 (5), 747-755.

Bueno, R. K. (2014). Relações entre envolvimento paterno com filhos adotivos e estrutura familiar. Dissertação de Mestrado, Programa de Pós-graduação em Psicologia, Universidade Federal de Santa Catarina, Florianópolis, SC.

Bueno, R. K. \& Vieira, M. L. (2014). Análise de estudos brasileiros sobre o pai e o desenvolvimento infantil. Psicologia Argumento, 32(76), 151-159.

Bustamante, V. \& Trad, L. A. B. (2005). Participação paterna no cuidado de crianças pequenas: Um estudo etnográfico com famílias de camadas populares. Cadernos de Saúde Pública, 21(6), 1865-1874.

Cabrera, N. J. \& Bradley, R. H. (2012). Latino Fathers and Their Children. Child Development Perspectives, 6 (3), 232-238.

Cabrera, N. J., Tamis-LelMonda, C. S., Bradley, R. H., Hofferth, S., \& Lamb, M. E. (2000). Fatherhood in the twenty-first century. Child Development, 71(1), 127-136.

Cia, F., Pamplin, R. C. O., \& Williams, L. C. A. (2008). O impacto do envolvimento parental no desempenho acadêmico de crianças escolares. Psicologia em Estudo, 13(2), 351-360.

Davies, P. T., Cummings, E. Mas \& Winter, M. A. (2004). Pathways between profiles of family functioning, child security in the interparental subsystem, and child psychological problems. Development and Psychopathology., 16, 525-550.

D’Avila-Bacarji, K. M. Gu, Marturano, E. M., \& Elias, L. C. S. (2005). Suporte parental: um estudo sobre crianças com queixas escolares. Psicologia em Estudo, 10(1), 110-115.

Dessen, M. A. \& Ribeiro, M. O. (2013). Envolvimento Paterno Durante o Nascimento dos Filhos: Pai "Real" e "Ideal" na Perspectiva Materna. Psicologia: Reflexão e Crítica, 26 (1), 184-192.

Dubeau, D., Devault, A., \& Paquette, D. (2009). L'engagement paternel, un concept aux multiples facettes. In D. Dubeau, A. Devault, \& G. Forget (Eds.), La paternité au XXI sièle (pp. 71-98). Québec, CAN: Les Presses de l'Université Laval.

Fagundes, A. J. F. M. (1999). Descrição, definição e registro de comportamento (12a ed.). São Paulo: Edicon.

Falceto, 0. G, Fernandes, C. L., Baratojo, C., \& Giugliani, E. R. J. (2008). Fato- 
res associados ao envolvimento do pai nos cuidados do lactente. Revista Saúde Pública, 42(6), 1034-1040.

Ferreira, S. L. G. \& Triches, M. A. (2009). $\mathrm{O}$ envolvimento parental nas instituições de educação infantil. Revista Pedagógica(Chapecó), 11(22), 39-55.

Flick, U. (2009). Uma introdução à pesquisa qualitativa (3a ed.) Porto Alegre: Artmed.

Gabriel, M. R. \& Dias, A. C. G. (2011). Percepções sobre a paternidade: Descrevendo a si mesmo e o próprio pai como pai. Estudos de Psicologia, 16(3), 253-261.

Genesoni, L. \& Tallandini, M. A. (2009). Men's psychological transition to fatherhood: An analysis of the literature, 1989-2008. Birth, 36(4), 305-318.

Gergen, K. J., \& Gergen, M. (2010). Construcionismo social: um convite ao diálogo. Rio de Janeiro: Noos.

Goetz, E. R. \& Vieira, M. L. (2009). Percepções dos filhos sobre aspectos reais e ideais do cuidado parental. Estudos de Psicologia (Campinas), 26(2), 195-203.

Gomes, L. B. (2015). Envolvimento parental, desenvolvimento social e temperamento de pré-escolares: um estudo comparativo em Santa Catarina e Montreal. Tese de Doutorado, Programa de Pós-graduação em Psicologia, Universidade Federal de Santa Catarina, Florianópolis, SC.

Grandesso, M. (2000). Sobre a reconstrução do significado: uma análise epistemológica e hermenêutica da prática clínica. São Paulo: Casa do Psicólogo.

Grzybowski, L. S. \& Wagner, A. (2010). O envolvimento parental após a separaçã-o/divórcio. Psicologia: Reflexão e Crítica, 23(2), 289-298.

Lamb, M. E. (Org.). (1997). The role of the father in child development. New York: John Wiley \& Sons.
Lamb, M. E. (2000). The history of research on father involvement: an overview. In H. E. Peters, G. W. Peterson, S. K. Steinmetz, \& R. D. Day (Eds.), Fatherhood: research, interventions and policies (pp. 23-42). Nova York: Haworth Press.

Lamb, M. E.s, Frodi, M., Hwang, C., \& Frodi, A. (1983). Effects of paternal involvement for mothers and fathers. Child Development, 54(2), 450-458.

Lamb, M. E., Pleck, J. H., Charnov, E. L., \& Levine, J. A. (1985). Paternal behavior in humans. American Zoologist, 25(3), 883-894.

Matos, M. G. Magalhães, A. S., Féres-Carneiro, Try \& Machado, R. N. (2017). Construindo o vínculo pai-bebê: a experiência dos pais. Psico-USF, 22(2), 261-271.

McBride, B. A., Brown, G. L., Bost, K. K., Shin, N., Vaughn, B., \& Korth, B. (2005). Paternal identity, maternal gate keeping, and father involvement. Family Relations, 54(3), 360-372.

Monteiro, L., Fernandes, M., Veríssimo, M., Costa, I. P., Torres, N., \&, Vaughn, B. E. (2010). Perspectiva do pai acerca do seu envolvimento em famílias nucleares. Associações com o que é desejado pela mãe e com as características da criança. Revista Interamericana de Psicologia, 44(1), 120-130.

Oliveira, J. L. A. Pr (2017). O envolvimento paterno no contexto do divórcio/separação conjugal. Dissertação de Mestrado, Programa de Pós-graduação em Psicologia, Universidade Federal de Santa Catarina, Florianópolis, SC.

Paquette, D. (2004). Le rôle du père dans la capacité du garçon à gérer son agressivité. Revue de psychoéducation, 33(1), 61-73.

Paraventi, L., Bittencourt, I. G., Schulz, M. L. C., Souza, C. D. de, \& Vieira, M. L. (2017). A percepção de pessoas 
sem filhos sobre a função paterna. Psico, 48(1), 1-11.

Piccinini, C. Ang Levandowski, D. C., Gomes, A. G.s Lindenmeyer, D., \& Lopes, R. S. (2009). Expectativas e sentimentos de pais em relação ao bebê durante a gestação. Estudos de Psicologia (Campinas), 26(3), 373-382.

Pimenta, M., Veríssimo, M.s, Monteiro, L., \& Costa, I. P. (2010). O envolvimento paterno de crianças a frequentar o jardim de infância. Análise Psicológica, 4(28), 565-580.

Pleck, J. H. (1997). Paternal involvement: levels, sources and consequences. In M. E. Lamb (Ed.), The role of the father in child development (pp. 66-103). New York: John Wiley \& Sons.

Sampieri, R. H., Collado, C. F., \& Lucio, M. P. B. (2013). Metodologia de pesquisa. Porto Alegre: Penso.

Schober, Pr S. (2012). Paternal child care and relationship quality: A longitudinal analysis of reciprocal associations. Journal of Marriage and Family, 74(2), 281-296.

Schoppe-Sullivan, S. Ja, Brown, G. L., Cannon, E. A., Mongelsdorf, S. C., \& Szewczyk S. M. (2008). Maternal gate keeping, coparenting quality and fathering behavior in families with infants. Journal of Family Psychology, 22, 389-398.

Schmidt, B. (2012). Relacionamento conjugal e temperamento de crianças com idade entre quatro e seis anos. Dissertaçao de Mestrado, Programa de Pós-graduação em Psicologia,Universidade Federal de Santa Catarina, Florianópolis, SC.

Silva, M. R. \& Piccinini, C. A. (2007). Sentimentos sobre a paternidade e o envolvimento paterno: um estudo qualitativo. Estudos de Psicologia, 24(4), 561-573.

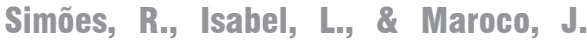
(2010). Paternal involvement in a group of fathers of elementary school children. Psicologia, Saúde \& Doenças, 11(2), 339-356.

Souza, C. L. C. \& Benetti, S. Pr (2009). Paternidade contemporânea: levantamento da produção acadêmica no período de 2000 a 2007. Paidéia, 19(42), 97-106.

Staudt, A. C. P. \& Wagner, A. (2008). Paternidade em tempos de mudança. Psicologia: Teoria e Prática, 10(1), 174-185.

Turcotte, G. \& Gaudet, J. (2009). Conditions favorables et obstacles à l'engagement paternel: un bilan des connaissances. In D. Dubeau, A. Devault, \& G. Forget (Eds.), La paternité au XXI sièle (pp. 3970). Québec, CAN: Les presses de l'Université Laval.

Wagner, A. Predebon, J., Mosmann, C., \& Verza, F: (2005). Compartilhar Tarefas? Papéis e funções de pai e mãe na família contemporânea. Psicologia: Teoria e Pesquisa, 21(2), 181-186.

\section{MARIANA SCHUBERT BACKES}

Doutoranda. Programa de Pós-Graduação em Psicologia. Universidade Federal de Santa Catarina (UFSC). Florianópolis, SC, Brasil.

E-mail: mari backes@hotmail.com

\section{ANA PAULA SESTI BECKER}

Doutoranda. Programa de Pós-Graduação em Psicologia. Universidade Federal de Santa Catarina (UFSC). Florianópolis, SC, Brasil.

E-mail: anapaulabecker.psicologia@ gmail.com 
MARIA APARECIDA CREPALDI

Doutora Docente. Programa de Pós-Graduação em Psicologia. Universidade Federal de Santa Catarina (UFSC). Florianópolis, SC, Brasil.

E-mail: maria.crepaldi@gmail.com

\section{MAURO LUÍS VIEIRA}

Doutor Docente. Programa de Pós-Graduação em Psicologia. Universidade Federal de Santa Catarina (UFSC). Florianópolis, SC, Brasil.

E-mail: maurolvieira@gmail.com 